\title{
MÃO-SOBRE-A-BOCA COMO ESTRATÉGIA DE MANEJO COMPORTAMENTAL EM ODONTOPEDIATRIA, VILÃ OU MOCINHA? REVISÃO NARRATIVA DE LITERATURAtp://doi.org/10.48195/sepe2021-077
}

\author{
Estefânia Bisognin Cervo ${ }^{1}$, Fabiana Grassmann da Silveira ${ }^{1}$, Cristiane \\ Medianeira Savian², Cândida Bonadiman Jung ${ }^{3}$, Maurício Barbieri Mezomo ${ }^{4}$, \\ Letícia Westphalen Bento ${ }^{4}$, Simone Pippi Antoniazzi ${ }^{4}$, Bianca Zimmermann \\ Santos 5
}

\section{RESUMO}

O objetivo deste trabalho é realizar uma revisão de literatura sobre a técnica de controle comportamental aversivo de contenção do paciente odontopediátrico "mão sobre a boca". As buscas foram realizadas na base de dados Google Scholar utilizando as seguintes palavras-chave e descritores do DeCS: "criança", "técnica de condicionamento", "mão-sobre-a-boca", "ansiedade odontológica", combinados pelo operador booleano AND. Não foi realizada a delimitação temporal. Foram incluídos somente artigos que contemplassem a temática proposta. As buscas foram realizadas no mês de julho de 2021. A técnica da "mão sobre a boca" consiste em o operador obstruir a cavidade bucal do paciente com a mão. Assim, a criança é obrigada a interromper gritos ou choros. Há linhas de ponderação que são contrárias a essa técnica, mas há também aqueles profissionais que veem esse método como um adequado meio de obrigar o paciente a prestar atenção no atendimento odontológico. Conclui-se que a técnica, apesar da literatura considera-la útil, ainda que o profissional tenha preparo para realiza-la, a mesmo tem sido desaconselhada nos últimos anos, devido ao impacto negativo que pode causar no desenvolvimento psicológico infantil

Palavras-chave: criança, ansiedade odontológica, técnica de comportamento, mãosobre-a-boca.

Eixo temático: Saúde Materno Infantil (SMI).

\section{INTRODUÇÃO}

\footnotetext{
${ }^{1}$ Acadêmico do Curso de Odontologia - Universidade Franciscana -UFN estefaniacervo98@gmail.com, fabiana.gsilveira@ufn.edu.br

${ }^{2}$ Mestre em Saúde Materno Infantil - Universidade Franciscana - UFN cmsavian@hotmail.com

${ }^{3}$ Mestranda em Saúde Materno Infantil - Universidade Franciscana - UFN candidabonadiman@yahoo.com.br

${ }^{4}$ Professor(a) do Curso de Odontologia - Universidade Franciscana - UFN mauriciomezomo@gmail.com

${ }^{5}$ Orientadora. Professora do Curso de Odontologia - Universidade Franciscana - UFN biancazsantos@ufn.edu.br
} 
Durante o atendimento odontopediátrico podem acontecer muitos obstáculos. O relacionamento harmônico dentista-paciente é fundamental para conseguir ter um bom atendimento e para o acolhimento quando houver contratempos no momento clínico (GOMES; SILVA, 2017). Além disso, o relacionamento harmônico com os pais ou responsáveis deve ser efetivo, já que os responsáveis têm papel fundamental no comportamento colaborativo da criança.

A Odontopediatria é marcada pela complexidade das atividades relacionais, sendo que os especialistas da área frequentemente se deparam com fobias ou ansiedade, não cooperação de pacientes e ações familiares complexas (BARRETO et al., 2015). Dessa forma, descobrir os motivos que fazem com que o paciente infantil tenha comportamento negativo é o passo principal para facilitar o atendimento e o condicionamento, uma vez que facilitará o momento clínico (PIRES, 2005).

Para o auxiliar o manejo de comportamento, existem técnicas de controle de comportamento não-aversivas como o reforço positivo, distração, relaxamento muscular, falar-mostrar-fazer, controle de voz, e as aversivas como a mão-sobre-aboca e a contenção física. O dentista deve ter embasamento para escolher a melhor técnica, levando em consideração a idade, histórico, nível de medo e ansiedade e fase de desenvolvimento da criança, além da aceitação dos pais e dificuldade do tratamento (MATOS; FERREIRA; VIEIRA, 2018).

O objetivo deste trabalho é realizar uma revisão de literatura descrevendo os principais aspectos que permeiam a técnica de controle comportamental aversivo de contenção do paciente odontopediátrico "mão sobre a boca".

\section{METODOLOGIA}

O estudo trata de uma revisão narrativa de literatura e para o desenvolvimento desta, foi realizada uma busca de artigos referentes ao tema 
estudado, na base de dados Google Scholar. A pesquisa foi realizada no mês de julho de 2021. Foram utilizados as seguintes palavras chave e descritores do DeCS: "criança", "controle de comportamento", "técnica mão-sobre-a-boca", "ansiedade odontológica”, combinados pelo operador booleano "AND”. Foi realizada a leitura dos títulos e resumos de todos os artigos encontrados, para adequada inclusão dos trabalhos relacionados ao tema. Como critério de inclusão foi considerado: artigos que contemplassem a temática proposta, publicados em português. $\mathrm{O}$ critério de exclusão estabelecido foi artigos que não estivessem com o texto completo disponível.

\section{RESULTADOS E DISCUSSÃO}

Corretamente executada, a técnica da mão-sobre-a-boca é um procedimento que interrompe o comportamento histérico do paciente, mas é indicado em situações específicas. É uma técnica utilizada apenas em crianças em que o comportamento impossibilita um adequado tratamento odontológico. Sendo utilizado em crianças com maturidade para compreender que a ação não é de caráter punitivo e que a técnica auxilia no atendimento do profissional (LEVITAS, 1974).

Para a criança que resiste à terapêutica com um temperamento violento e descontrolado a mão-sobre-a-boca é um método eficaz para obter sua ajuda (CRAIG, 1971). A aplicação adequada de mão-sobre-a-boca tem sido descrita por Levitas (1974), onde o profissional coloca a sua mão sobre a boca da criança, e fala calma e repetidamente ao seu ouvido, palavras de tranquilidade que se ele parar de gritar o mesmo remove a sua mão da boca.

Normalmente, depois de aplicar esta técnica, o paciente infantil abandona o comportamento histérico. Se realmente ocorrer, é fundamental que o dentista reforce o comportamento positivo, com elogios. Caso a criança faça o contrário, como se 
debater na cadeira após a mão-sobre-a-boca ser removida, a técnica deve ser aplicada novamente. Logo, a criança deve ser estoicamente criticada, que, uma vez removida a mão, ela deve ajudar, ficar sossegada, abrir a boca e escutar o dentista (GUEDES-PINTO; CORRÊA, 1995).

No entanto, alguns profissionais preferem não usar a técnica mão-sobre-aboca por acreditarem no condicionamento através das técnicas de controle de comportamento não aversivo. Também por ser uma técnica polêmica e controversa, e ainda usam a técnica mão-sobre-a-boca com dúvidas quanto à sua possibilidade de traumatizar o paciente (LEVITAS, 1974).

A Academia Americana de Odontopediatria, em seu manual de referência (1999-2000), cita que a manobra deve ser aplicada em crianças ditas como regulares, saudáveis capazes de compreender mas que demonstram um comportamento custoso e histérico frente ao tratamento odontológico. Hartamen e colaboradores (1985) referem que, entre 1773 pacientes atendidos durante 10 sessões, percebeu-se que $9,7 \%$ dos pacientes odontopediátricos passaram pela técnica mão-sobre-a-boca (maioria em única sessão). Desse total, apresentaram maior cooperação posterior durante as consultas. Isso mostra que a técnica mãosobre-a-boca é um método seguro e efetivo para lidar com crianças pouco cooperativas, atuando no estabelecimento de uma maior comunicação entre profissional e paciente.

Dentro da Odontopediatria, por lidar com seres humanos em primordial estágio de desenvolvimento emocional, depara-se com situações delicadas. Então, diferentes desafios exigem diferentes métodos, sendo que cada um adequa-se nos diferentes contextos. A odontopediatria é marcada por lidar, em suas atividades, com muitos desafios de cunho psicológico, deparando-se com fobias, não 
cooperação de paciente, dinâmica familiar complexa, agressividade, entre outros (BARRETO et al., 2015).

É fundamental elucidar que a técnica mão-sobre-a-boca tem seu protocolo de uso. Não é um manejo "grosseiro" e requer cautela por parte do profissional. Levitas (1974), traz a descrição ideal da técnica caracterizada por, primeiramente, saber identificar o momento ideal do seu uso. É preciso haver necessidade e viabilidade. Posteriormente, com calma, o operador cobre a boca do paciente, com cuidado para não atrapalhar seu processo respiratório, e explicar, calmamente em baixo tom, que a mão só será removida após o controle de comportamento da criança. Naturalmente, a criança assente e se tranquiliza. Tendo em vista que o objetivo é prática é acalmar a criança e garantindo que esse processo não seja traumático, não há razões para relegar seu uso perpetuamente.

Ferreira e colaboradores (2003) concluem que a maioria dos Odontopediatras acreditam que a técnica mão-sobre-a-boca traz efeitos psicológicos positivos e negativos para a criança. Em contraposição parcial, Sant'anna e colaboradores (2020) citam que as consequências da técnica mão-sobre-a-boca pode trazer danos físicos e também psicológicos, e isso é prejudicial, já que a criança está em formação, então afirmam que se deve escolher modos de contenção que não agridam o ser humano como um todo. Em concordância com os últimos autores, Torres, Souza e Cruz (2020) completam que desde o momento do reconhecimento do grau de ansiedade da criança, várias outras técnicas de manejo e atenuação poderão ser empregues com o intuito que os atendimentos sejam menos desgastantes para o paciente e profissional.

Por outro lado, há muitos autores que não fazem o uso desta técnica por receio de serem julgados de alguma forma. Bigella e colaboradores (2003) mostram 
que é fundamental que o odontopediatra ao realizar a técnica esclareça previamente aos pais ou responsáveis pela criança e colete a autorização por escrito dos mesmos para a realização desta metodologia para não haver desentendimentos. Em observação, Ferreira e colaboradores (2003) analisou que a maioria dos advogados afirma que a técnica não traria consequências judiciais para o odontopediatra se este tomasse o cuidado de conversar com os responsáveis e solicitar-lhes o termo de consentimento.

Por outro lado, a questão do não acompanhamento psicológico e uso da psicologia no atendimento é outro fator para não realizar a técnica. Resende (2020) discute que em busca de sucesso no tratamento é necessário incluir o terapeuta, melhorando a educação específica desse paciente, oferecendo orientações para trabalhar diante deles para não haver questões negativas para o CD e a criança. Concordando com a temática psicológica na questão ligada ao trauma, Lima, Maia e Bezerra (2016) ressaltaram que conhecimentos da psicologia aplicados à odontopediatria possibilitam um melhor e mais integrado relacionamento profissionalpaciente, visto que a infância é caracterizada como um período crítico para o desenvolvimento do medo e/ ou ansiedade, sendo este um motivo significativo para ausência de adolescentes e adultos no consultório odontológico. Logo, Gustafsson (2007) relata que a psicologia não deve ser negligenciada antes, durante e após os procedimentos, pois crianças com problemas comportamentais só geraram estresse no atendimento impossibilitando esse.

As vantagens encontradas no método de contenção "mão-sobre-a-boca" do paciente odontopediátricos são percebidas quando o paciente passa a prestar atenção no profissional, não interrompendo-o com falas ou manifestações sonoras tais como o choro. O dentista precisa de tranquilidade para explicar e para desenrolar sua consulta. Enquanto a criança recupera a calma, a mão é removida de sua boca. 
Essas diretrizes foram expostas por Santiago, De Souza e De Almeida (2021). Os desafios, por outro lado, mostram-se pontuais no que diz respeito a crianças que convivem com limitações físicas, emocionais ou psicológicas. Resende (2020) menciona com bastante clareza que é necessário que se conheça e que se respeite cada etapa do desenvolvimento do paciente odontopediátrico, acolhendo e empregando a técnica que for mais adequada ao individualismo da criança.

Os achados bibliográficos foram unânimes ao destacar que essa técnica polêmica tem suas ressalvas. Não há como defender seu livre uso, tendo em vista que cada criança é única e reverbera os acontecimentos de forma única e pessoal. $\mathrm{A}$ técnica mão-sobre-a-boca não é um manejo de rotina, é sim vista como um último recurso, se apresentando como um método seguro e eficaz quando um maior controle sobre o paciente infantil se fizer necessário (SANT'ANNA, 2020).

Marques, Gradvohl e Maia (2010) mostraram que o preparo psicológico antes do atendimento na cadeira do dentista é fundamental para conseguir a colaboração e cooperação da criança. Atividades lúdicas como demonstrar em manequim e falar a procedimento de forma adaptada ao paciente de forma infantil possibilita à criança aprender e resignar seu pré comportamento antes do atendimento (SILVEIRA, 2014).

\section{CONCLUSÃO}

Os achados bibliográficos foram unânimes ao destacar que essa técnica polêmica tem suas ressalvas. Não há como defender seu livre uso, tendo em vista que cada criança é única e reverbera os acontecimentos de forma única e pessoal. É de extrema importância que nenhuma abordagem do dentista gere traumas na criança ou agrave algum quadro de trauma já existente. Infere-se, através dos trabalhos encontrados, que desde a formação acadêmica, o profissional deve ser advertido e instruído de como lidar corretamente com pacientes pediátricos. Assim, 
no contexto atual embora alguns autores orientem que não se pode preterir imediatamente a técnica de contenção "mão sobre a boca", no contexto de humanização trabalhado atualmente, ela não vem sendo mais recomendada.

\section{REFERÊNCIAS}

BARReto, R. A; BARREto, M. A. C; CoRRÊA, M. S. N. P. Psicanálise e odontopediatria: ofício da comunicação. Estudos de Psicanálise, n. 44, p. 83-90, 2015.

CRAIG, W. Hand over mouth technique. J Dent Child, v. 28, n. 6, p. 387-389, 1971.

FERREIRA, K. D. et al. Mão-sobre-a-boca: Avaliação do Uso da Técnica em Belo Horizonte. Rev Ibero-am Odontopediatrica Odontologica Bebê, v. 6., n. 34, p. 447489, 2003.

GUEDES-PINTO, A. C, CORRÊA, M. S. N. P. Manejo da criança no consultório. Odontopediatria, p. 209-229, São Paulo, 1995.

GOMES, G. O; Silva K. S. Métodos de controle do comportamento para atendimento em odontopediatria. Capa, v. 2, n. 1, 2017.

GUSTAFSSON, A. Psychosocial concomitants to dental fear and behaviour management problems. Int J Pediatr Dentist, v. 17, n. 6, p. 449-459, 2007.

LEVITAS, T. C. Home: hand over mouth exercise. J Dent Child, v. 41, n. 4, p. 178$1781,1974$.

LIMA, K. M. A, Maia, A. H. N, BEZERRA, M. H. O. Psicologia e odontopediatria: possibilidade de atuação em uma clínica - escola. Rev Exp Cat Saú, v. 1, n. 1, 2016.

MARQUES, K. B. G.; GRADVOHL, M. P. B.; Maia, M. C. G. Medo e ansiedade prévios à consulta odontológica em crianças do município de acaraú-ce. Rev Bras Prom Saú. v. 23, n.4. p.358-367, 2010.

MATOS, L. B; FERREIRA, R. B; VIEIRA, L. D. S. Manejo de comportamento em crianças com ansiedade e estresse em clínica de Odontopediatria: Revisão de Literatura. R Odontol Planal Cent., v. 4, n. 1, p. 111, 2018. 
PIRES, V. R. Análise da reação emocional do paciente odontopediárico após anestesia parcial por meio de escala análoga visual. Pesq. Bras. Odontoped. Clin. Integr., v. 5, n. 2, p. 127-131, 2005.

RESENDE, T. S. Atendimento odontológico a crianças autistas: revisão de literatura. Monografia (graduação) - Faculdade de Odontologia, Universidade de Taubaté, p. 1-37, 2020.

SANT'ANNA, R. M. et al. Aspectos éticos e legais das técnicas de manejo de comportamento em odontopediatria: uma revisão narrativa da literatura. Rev Bras Odont Legal, v. 7, n. 2, p.64, 2020.

SANTIAGO, E. P.; DE SOUSA, T. B.; DE ALMEIDA, S. A. Odontofobia na infância e a conduta do cirurgião-dentista: uma revisão integrativa da literatura. Facit Business Technol J, v. 1, n. 26, p. 111, 2021.

SILVEIRA, C. Z. A importância do Lúdico na Odontopediatria: Revisão de Literatura. Monografia (graduação) - Faculdade de Odontologia, Universidade Tiradentes, Aracaju, p. 1-21, 2014.

TORRES, M. E. B. B; SOUZA, K. L. B.; CRUZ, V. S. A. Estratégias de controle do medo e ansiedade em pacientes odontopediátricos: revisão de literatura. Rev Eletr Ac Saú, v. 12, n. 11, p. 5, 2020. 